\title{
A 16-year Longitudinal Cohort Study of Incidence and Bacteriology of Necrotising Fasciitis in England
}

\author{
David M. S. Bodansky ${ }^{1}$ Irena Begaj ${ }^{2}$ - Felicity Evison ${ }^{2} \cdot$ Mark Webber $^{3}$ • \\ Ciaran B. Woodman ${ }^{4} \cdot$ Olga N. Tucker $^{2}$
}

\begin{abstract}
Background Necrotising fasciitis (NF) is a rapidly progressive, destructive soft tissue infection with high mortality. The primary aim of this study was to evaluate the incidence and mortality of NF amongst patients admitted to English National Health Service (NHS) hospitals. The secondary aims included the identification of risk factors for mortality and causative pathogens.

Methods The Hospital Episodes Statistics database identified patients with NF admitted to English NHS Trusts from $1 / 1 / 2002$ to $31 / 12 / 2017$. Information on patient demographics, co-morbid conditions, microbiology specimens, surgical intervention and in-hospital mortality was collected. Uni- and multivariable analyses were performed to investigate factors related to in-hospital mortality.

Results A total of 11,042 patients were diagnosed with NF. Age-standardised incidence rose from 9 per million in 2002 to 21 per million in 2017 (annual percentage change $=6.9 \%$ ). Incidence increased with age and was higher in men. Age-standardised mortality rate remained at $16 \%$ over the study period, while in-hospital mortality declined. On multivariable analysis, the following factors were associated with increased risk of in-hospital mortality: emergency admission, female sex, history of congestive heart failure, peripheral vascular disease, chronic kidney disease and cancer. Admission year and diabetes, which was significantly prevalent at $27 \%$, were not associated with increased risk of mortality. Gram-positive pathogens, particularly Staphylococci, decreased over the study period with a corresponding increase in Gram-negative pathogens, predominantly E. coli.

Conclusion The incidence of NF increased markedly from 2002 to 2017 although in-hospital mortality did not change. There was a gradual shift in the causative organisms from Gram-positive to Gram-negative.
\end{abstract}

Olga N. Tucker

o.tucker@bham.ac.uk

David M. S. Bodansky

david.bodansky@nhs.net

1 The Departments of Surgery, Royal Liverpool and Broadgreen University Hospitals Trust, Prescot Street, Liverpool L7 8XP, UK
2 Health Informatics and Surgery, University Hospitals Birmingham NHS Foundation Trust, Birmingham B15 2GW, UK

3 Quadram Institute Bioscience, Norwich NR4 7UQ, UK

4 Cancer Sciences, University of Birmingham, Birmingham B15 2SG, UK 


\section{Introduction}

Necrotising fasciitis (NF) is a rapidly progressing soft tissue infection that frequently results in permanent disability and death despite parenteral antibiotic therapy and aggressive surgical management [1-4]. NF usually starts as a local infection from an abrasion, scratch or bite [5, 6]. The patient may present with cellulitis, which rapidly progresses with pain disproportionate to the area of infection [7]. The infection spreads to the fascial layer and then laterally along this plane with superficial tissue necrosis. Diabetes, renal disease and increasing age have been associated with poor outcomes $[8,9]$.

Necrotising fasciitis may be caused by a variety of aerobic and facultative anaerobic bacterial species, but is frequently polymicrobial. As many as 4 or 5 species may be cultured and the contribution of each to the pathogenesis of the disease is often not clear [1, 10]. Infections have been divided into three categories determined by the isolated species into polymicrobial, Group A streptococcal (80-90\%) and Gram-negative rods infections [8, 11-13].

The incidence of NF has been described in the USA, with 4.8 deaths per $1,000,000$ person years without a change in incidence between 2002 and 2013 [8]. In this study, by Arif and colleagues of 9871 cases of NF, streptococcal species were identified in 48\% (260/546) deaths with a microbiological diagnosis, staphylococcal species in $22 \%$ (119/546) and Gram-negative species in 21\% (114/ 546). In this study, diabetes, renal disease and obesity were associated with mortality. An increase in incidence has been reported in New Zealand from 0.18 per 100,000 person-years in 1990 to 1.69 in 2006 and mortality from 0 to 0.3 per 100,000 person-years. In this latter study, disease risk was the highest in the elderly, males, and Pacific and Maori populations; however, microbiology was not reported [14]. There are no studies describing the incidence in England, where the estimated incidence and microbiology are unknown [1, 14-18].

The primary aim of this study was to determine the incidence and associated mortality of NF in England. The secondary aims were to investigate risk factors for mortality and causative pathogens in patients admitted with a diagnosis of NF in English NHS Hospitals over the study period.

\section{Methods}

The Clinical Audit Committee of the University Hospitals Birmingham NHS Foundation Trust approved the study. Patients were identified from the Hospital Episode Statistics (HES) database, with those admitted to an English
NHS Hospital, who were discharged between 1 January 2002 and 31 December 2017. Patients with a diagnosis of $\mathrm{NF}$ were identified using the tenth revision of the International Classification of Disease (ICD-10) code M72.5 assigned to the diagnostic fields of the first episode of each admission and M72.6 when introduced in 2008 [19]. Transfers between hospitals (434 patients) and readmissions with the same diagnosis were excluded. Pre-specified patient level data items for collection were identified and extracted from HES to include the date of admission and discharge, the hospital attended, demographic characteristics (age, gender, ethnicity, socio-economic status by postcode), diagnostic (co-morbid conditions) and procedural (surgical debridement, fasciotomy, skin grafting) codes, microbiological samples taken (using ICD-10 codes) and in-hospital mortality. Search terms and synonyms for procedural interventions were selected from the Office of Population, Censuses and Surveys Classification of Surgical Operations and Procedures, 4th revision (OPCS-4) [20] (listed in Appendix A). The subgroup of patients admitted as an emergency who underwent surgery for NF were analysed.

\section{Statistical methods}

Age-standardised incidence rates were calculated using the European Standard Population 2013. Change over time was monitored using annual population change statistics obtained from ONS mid-year population estimates following the 2011 census. Data on diabetes mellitus (DM) prevalence were obtained through the Quality and Outcome Framework (QOF) [21]. Incidence rates of NF in the population with DM were determined using HES and QOF data. Social deprivation was classified by postal code (English Indices of Deprivation, Ministry of Housing, Communities and Local Government). In-hospital mortality was measured. Patients with missing gender and age were removed from the data set. Unknown categories for ethnicity and deprivation were included. Patients with missing microbiological data were excluded in the analysis of changes in the proportions of causative organisms. Univariable analysis was performed to identify factors influencing in-hospital mortality to include in a multivariable model. All analyses were conducted using Stata SE v13 [22].

\section{Internal validation}

To confirm the accuracy of NF diagnoses, a random sample of 12 hospitals was chosen from the 160 acute hospitals in England to provide a representative sample of the complete 
cohort. Patients with a diagnosis of NF (M72.5 in ICD-10) who underwent in-hospital surgical debridement were randomly selected at each of the 12 hospitals over the 10 -year study period using a computer-generated method by a trained, blinded coder at each Trust's coding department. A blinded Consultant Microbiologist at each hospital reviewed the microbiology and pathology records for tissue samples taken at surgery for each patient to determine the accuracy of the diagnosis. Pre-specified patient-level data were collected using an anonymised questionnaire. A diagnosis of NF was accepted as accurate in the presence of a positive culture of one or more pathogens known to cause NF from local tissue swabs and/or blood cultures, or histological necrosis in debrided fascial and subcutaneous local tissue at surgery or autopsy.

\section{Results}

\section{Data accuracy and missing data}

Initially, 14,659 admissions to hospital for NF were identified between 1 January 2002 and 31 December 2017, using the ICD10 code M72.5 and M72.6. Missing patient age or gender excluded 16 admissions. A further 285 admissions were excluded because they were not resident in England, and thus follow-up data were not reliable. There were 2067 patients who had multiple admissions, so only the first was kept for analysis, excluding 3314 admissions, leaving 11,042 patients. Coding completion for ethnicity improved over the study period from $72.6 \%$ in 2002 to $94 \%$ in 2017.

The validation study provided 275 randomly selected patients with an ICD-10 diagnosis of NF, which represented $4 \%$ of the total cohort who underwent in-hospital surgical debridement. In total, 212 patients had a record of a wound swab or tissue sampling at surgery of which 179 (81\%) had microbiological and/or pathological confirmation of NF.

\section{Patient characteristics}

There were 11,042 patients in the study with a median age at diagnosis of 58 years (IQR 26). There were 5819 (52.7\%) males, and the median male age was 57 (IQR 25) compared with 59 for females (IQR 28) (Table 1). The ethnic structure reflected that of the UK population (Table 1) [23]. There were 3111 patients $(28.2 \%)$ from the most deprived socio-economic quintile, compared with $1610(14.6 \%)$ from the least deprived (Table 1).

The most common co-morbidities were diabetes (2941; $26.6 \%)$, peripheral vascular disease (PVD) $(1537 ; 13.9 \%)$ and pulmonary disease $(1514 ; 13.7 \%)$ (Table 1$)$. The pelvic region and thigh were the most common site for NF (3029; $27.4 \%$ ) followed by the lower leg $(1271 ; 11.5 \%)$ (Table 1$)$. Only 640 patients $(5.8 \%)$ had been admitted with cellulitis in the 30 days preceding their NF admission. In total, 1551 (14.0\%) patients had been treated for cellulitis previously in hospital.

\section{Incidence and mortality of necrotising fasciitis}

The age-standardised rate of admissions of NF doubled from 2002 to 2017 ( $p<0.001$, Fig. 1). This increase was observed in both sexes and was higher for men at all ages than women, with rate of admission increasing with age. The rate of mortality of patients admitted with NF across the study period was $16 \%$ and did not change statistically $(p=0.237)$.

A multivariable analysis showed that in-hospital mortality was higher for women (OR 1.28; 1.16-1.41, $p<0.0001)$ yet was not significantly higher at 1 year $(p=0.573)$ compared to men. Patients from the most deprived socio-economic quintile had the highest rate of 1-year mortality. Co-morbidities significantly increased inhospital mortality with the exception of diabetes, which did not increase the in-hospital mortality (OR 1.01; 0.91-1.11, $p=0.9042$ ) (Table 2). Although most patients were emergency admissions, there were 951 elective hospital patients who later developed NF. Necrotising fasciitis of the extremities (the feet or hands) were associated with increased survival by one year (Table 3 ).

\section{Emergency admissions requiring surgery}

Of the subgroup of emergency admissions receiving surgery, there were 6764 patients in total with a median age of 57 (IQR 44-68 years). There were 3723 men (55.0\%), and the median male age was 56 (IQR 44-68) compared to 57 years for women (IQR 44-69). The ethnic structure was similar to the UK population with similar numbers of comorbidities (Table 1).

Surgical intervention became more common over the study period with 190 patients receiving an intervention (debridement, amputation or grafting) in 2002 compared to 602 in 2017. However, the timing of surgical intervention from admission remained constant across the study period with the median time from admission to surgery being 1 day: debridement 1 day; to amputation 1 day and skin grafting 12 days (IQR 5-22).

Patients who underwent surgery on the same day as admission were more likely to die during their admission than those operated on later $(23.1 \%$ vs. $20.2 \%, p=0.006)$ after accounting for all other factors (co-morbidities, age, socio-economic deprivation, etc.). This remained true for deaths at 30 and 90 days. 
Table 1 Patient demographics

\begin{tabular}{|c|c|c|}
\hline & & Patients $(\%)$ \\
\hline \multirow[t]{2}{*}{ Gender } & Male & $5819(52.7)$ \\
\hline & Female & $5223(47.3)$ \\
\hline \multirow[t]{9}{*}{ Age group } & Under 10 & $195(1.8)$ \\
\hline & $10-19$ & $152(1.4)$ \\
\hline & $20-29$ & $532(4.8)$ \\
\hline & $30-39$ & $1170(10.6)$ \\
\hline & $40-49$ & $1773(16.1)$ \\
\hline & $50-59$ & $2070(18.7)$ \\
\hline & $60-69$ & $2223(20.1)$ \\
\hline & $70-79$ & $1743(15.8)$ \\
\hline & $80+$ & $1184(10.7)$ \\
\hline \multirow[t]{5}{*}{ Ethnicity } & White & $9771(88.5)$ \\
\hline & Asian & $368(3.3)$ \\
\hline & Black & $279(2.5)$ \\
\hline & Chinese, Other & $186(1.7)$ \\
\hline & Unknown & $438(4.0)$ \\
\hline \multirow[t]{9}{*}{ Deprivation quintile } & 1-Most deprived & $3111(28.2)$ \\
\hline & 2 & $2413(21.9)$ \\
\hline & 3 & $1971(17.9)$ \\
\hline & 4 & $1832(16.6)$ \\
\hline & 5-Least deprived & $1610(14.6)$ \\
\hline & Unknown & $105(1.0)$ \\
\hline & Diabetes & $2941(26.6)$ \\
\hline & Peripheral vascular disease & $1537(13.9)$ \\
\hline & Pulmonary disease & $1514(13.7)$ \\
\hline \multirow[t]{4}{*}{ Co-morbidities } & Chronic kidney disease & $1134(10.3)$ \\
\hline & Congestive heart failure & $809(7.3)$ \\
\hline & Cancer & $1134(10.3)$ \\
\hline & Cellulitis with previous 30 days & $640(5.8)$ \\
\hline \multirow[t]{12}{*}{ Location } & Ankle and foot & $533(4.8)$ \\
\hline & Arm-Unspecified & $59(0.5)$ \\
\hline & Forearm & $279(2.5)$ \\
\hline & Hand & $218(2.0)$ \\
\hline & Leg & $240(2.2)$ \\
\hline & Lower leg & $1271(11.5)$ \\
\hline & Multiple sites & $868(7.9)$ \\
\hline & Other-including trunk, head etc. ${ }^{a}$ & $2855(25.9)$ \\
\hline & Pelvic region and thigh & $3029(27.4)$ \\
\hline & Shoulder region & $120(1.1)$ \\
\hline & Upper arm & $178(1.6)$ \\
\hline & Unspecified & $1392(12.6)$ \\
\hline
\end{tabular}

${ }^{\mathrm{a}}$ It is not possible to break down this division further

\section{Incidence and mortality for surgical patients}

Age-standardised incidence for NF patients requiring surgery increased from 4 to 20 per million across the study period (Fig. 2). However, the mortality rate of NF remained constant across the study period $(p=0.19)$. Agespecific rate of admission to hospital with NF was higher for men than women at all ages. 
Fig. 1 Age standardised rate of admissions to hospital for patients with necrotising fasciitis and of mortality. The rate of admissions rose from 9 per million population in 2002 to 16 per million in 2017 . The rate of admissions resulting in death remained constant across the study period

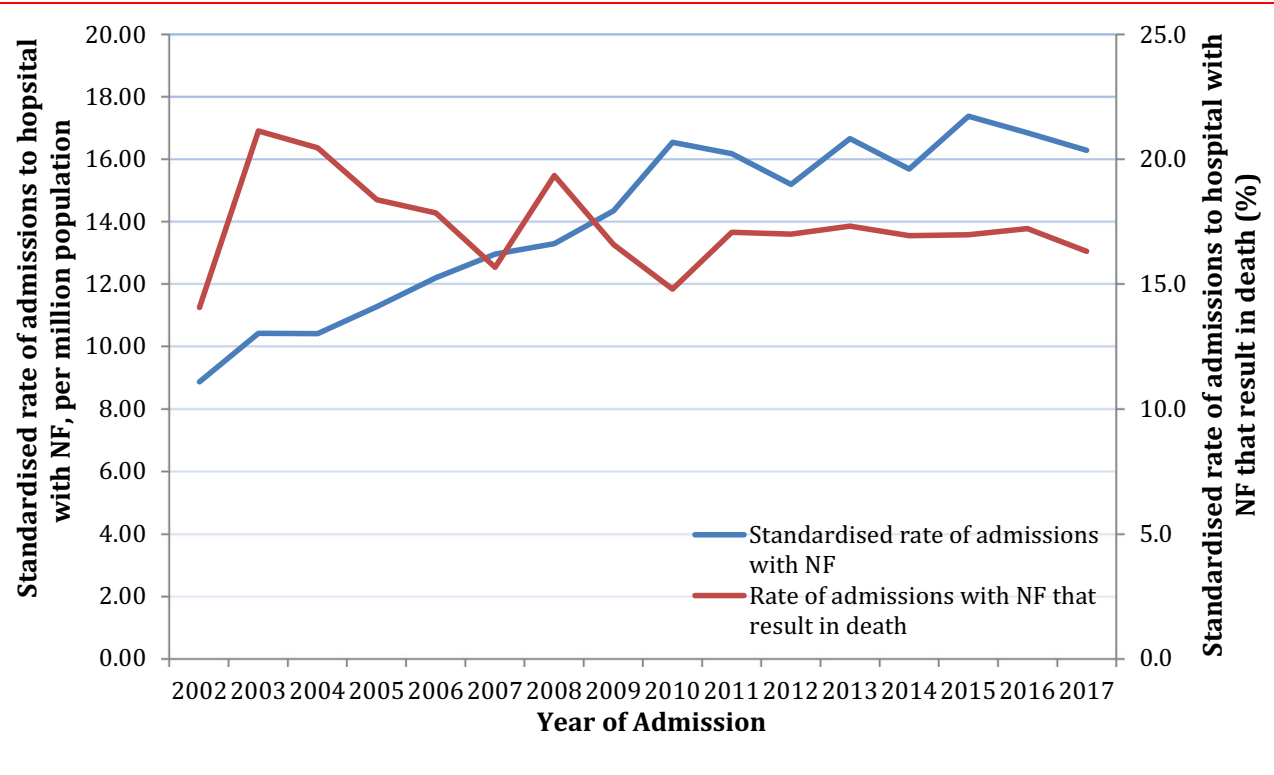

\section{Diabetes}

GP population data on diabetes were available from 2007 to 2017. During this time, the GP diabetic population rose from 3.7 to $6.7 \%$. However, the admissions of $\mathrm{NF}$ with diabetes rose from $25.4 \%$ in 2007 to $34.5 \%$ in 2017.

\section{Microbiological characteristics}

An identified pathogen was recorded in $4446(40.3 \%)$ patients. Of surgical patients, 3306 patients (48.9)\% had an identified pathogen compared to 1140 (26.6\%) patients treated non-surgically. Gram-positive species represented $63.71 \%$ of all isolated pathogens (range per year from 55.9 to $75.7 \%$ ) (Fig. 3). There was a reduction in the overall proportion of Gram-positive species isolated over time from $74.1 \%$ of all isolated pathogens in 2002 to $65.3 \%$ in 2017. This was largely due to a decrease in isolation of staphylococci, where from intra-operative samples numbers fell $44.3 \%$ of all recorded pathogens in 2002 to $21.1 \%$ in 2017 (Fig. 3). An increase in the overall proportion of Gram-negative species isolated from intra-operative samples rose from $22.7 \%$ of all recorded pathogens in 2002 to $32.9 \%$ in 2017 due mainly to an increase in E. coli and Klebsiella pneumoniae species (Fig. 3). Isolation of anaerobes was low throughout the study period at $0.95 \%$ (range $0.3-1.7 \%$ ) of all isolated species. No geographical hot spots of specific pathogens were identified.

Patients with Gram-negative species isolated had a mortality rate of $22.7 \%$ within hospital, compared to patients with Gram-positive species $(p=0.016)$. Patients with Gram-negative bacteriology also had higher mortality at 30 and 90 days and at 1 year than patients with Gram- positive species. In-hospital mortality was $22.7 \%$ (487) for patients with Gram-positive species, compared with $19.8 \%$ (444) for Gram-negative ( $p=0.016$ ). The 30-day mortality for Gram-positive species was 34.6\% (741), but Gramnegative was $26.9 \%$ (604) $(p<0.0001)$. However, the 90-day mortality rose to $41.5 \%$ (890) for Gram-positive compared to $33.3 \%$ (749) for Gram-negative and by one year, the Gram-positive mortality rate was $44.0 \%$ (943), but Gram-negative was $36.3 \%$ (816) $(p<0.0001)$.

\section{Discussion}

This study has demonstrated a marked increase in the incidence of NF admissions in England over a 16-year period from 2002 to 2017 (Fig. 1). The dates for the study period were chosen to evaluate 16 years of data and to encompass the census of 2011. In line with these findings, increased incidence of NF has been seen in other countries including New Zealand and USA [14]. The relationship to predisposing factors including DM, PVD, CKD, socioeconomic status, sex and age is consistent with previous studies [2, 24].

Patients with diabetes (DM) are four times over-represented in the cohort, importantly; however, their mortality was no greater than the rest of the population with NF. Patients with DM increased by $62.3 \%$ over the study period in line with increasing prevalence of DM worldwide, with the UK population of patients with diabetes increased by $72.9 \%$ across the study period [25]. The observed increased incidence of NF cannot therefore be explained by increased prevalence of DM. The proportion of chronic diseases predisposing to NF has been compared to that in the UK 


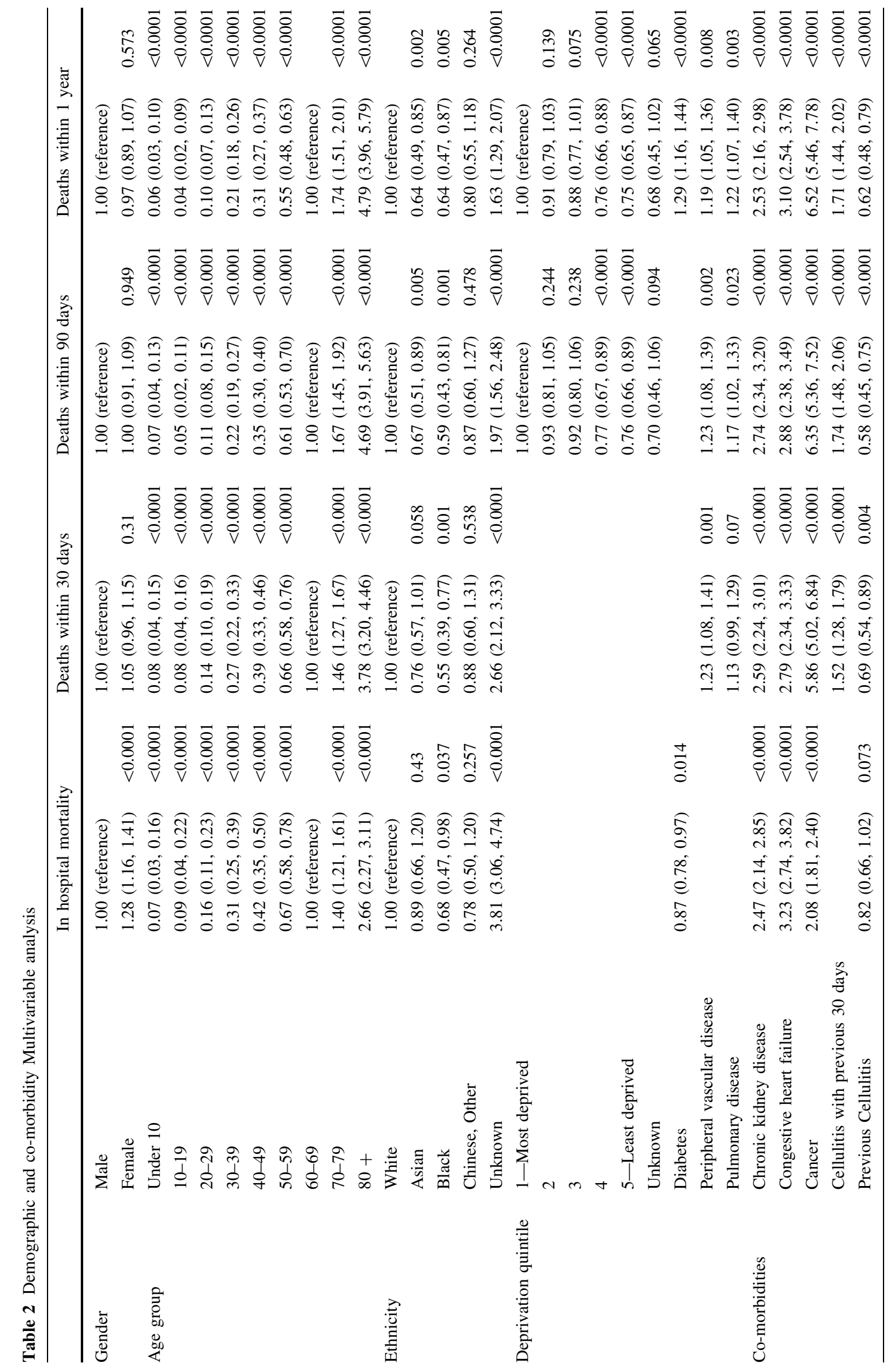




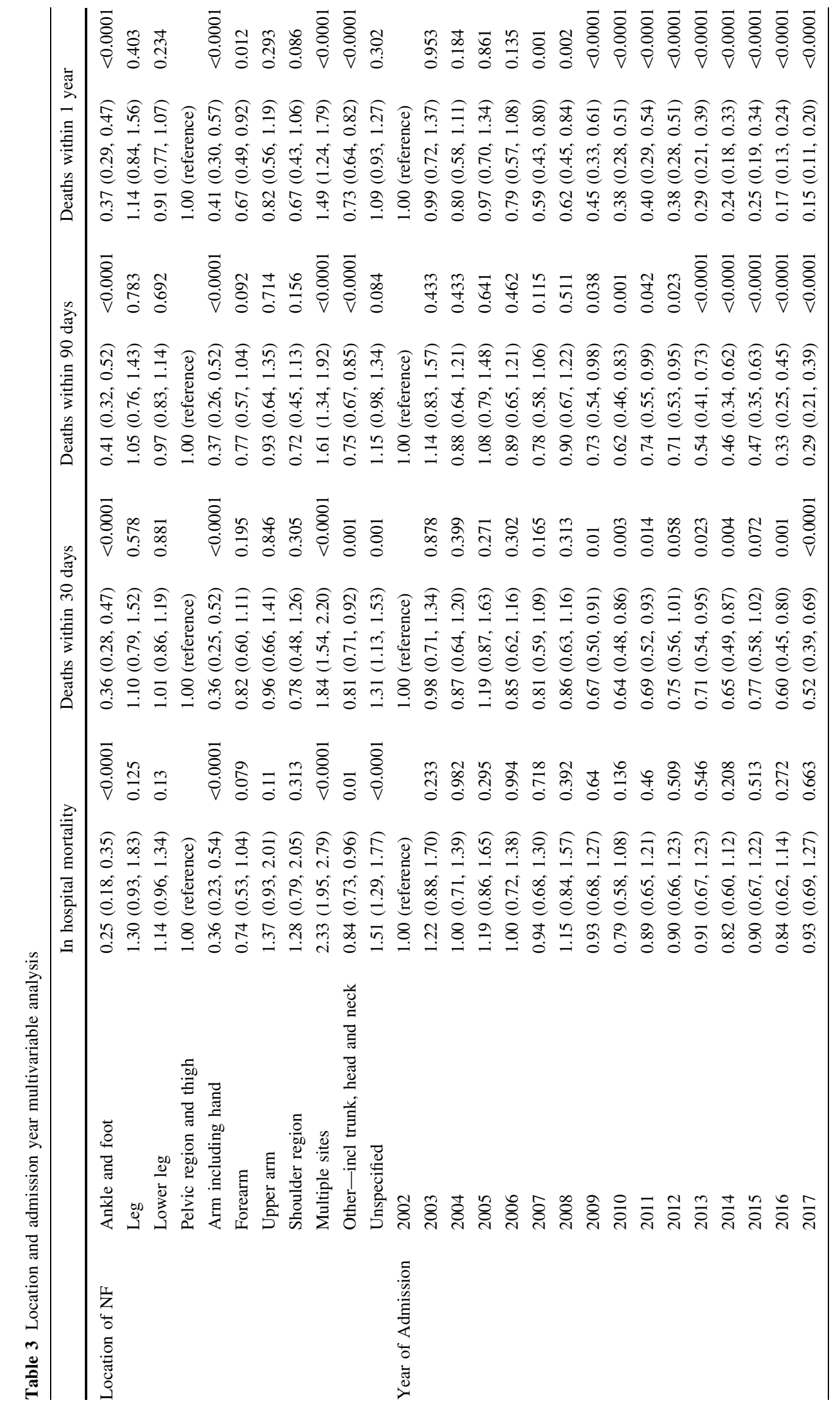




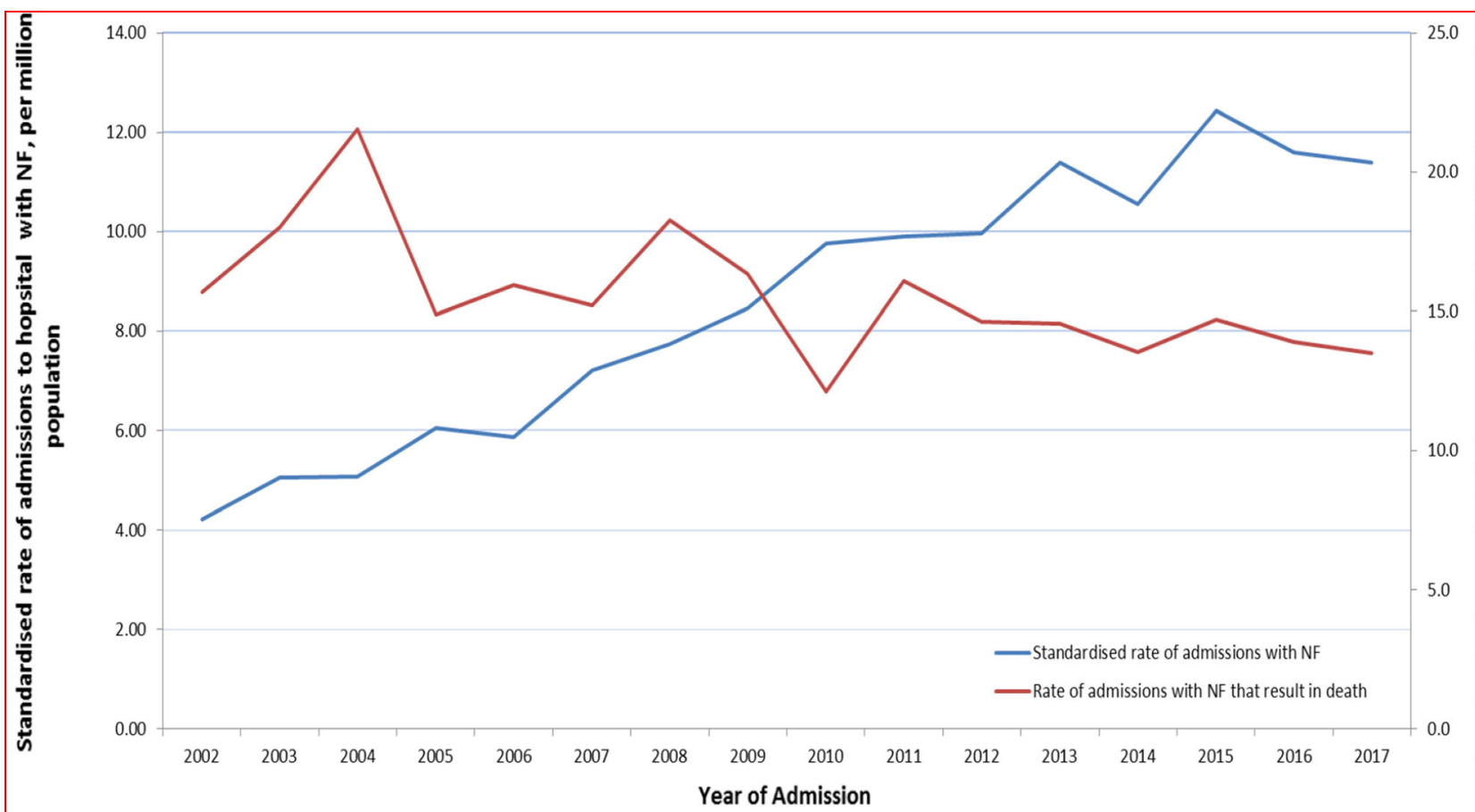

Fig. 2 Age standardised rate of admissions and of mortality for emergency admissions of patients with necrotising fasciitis requiring surgery. For those patients with necrotising fasciitis receiving surgery, the rate of admission rose from 4 per million population in 2002 to 12 per million population in 2017. However the standardised rate of admissions that resulted in death fell during the study period

population using the QOF in General Practice which has been previously validated but may underestimate the population [26-29].

An increase in the age-standardised death rate from NF was seen in line with the observed increased incidence (Fig. 1). Mortality remained constant across the study period. However, the age-standardised mortality rate reduced by $60 \%$ for patients admitted to hospital. An increased risk of in-hospital mortality was seen with emergency admission and in the presence of congestive heart failure, PVD and CKD. Although there has been a rise in the number of surgical interventions for patients admitted as an emergency, the time from admission to theatre remained unchanged over the study period. The rise in the number of patients undergoing operative intervention over the study period is likely due to increased awareness of NF and recognition of the value of early surgical debridement.

Of the cohort, 11,042 had 'NF' documented within patient medical records with 6764 undergoing surgery. Patients who underwent surgery on the day of admission had a higher 30- and 90-day mortality than those who underwent surgery after $24 \mathrm{~h}$. This cohort likely represents more unwell patients with a poorer prognosis requiring immediate life-saving intervention. The reasons for management of patients without surgical intervention were not possible to elucidate in this study. It may be that these patients were unfit or died before surgery. Alternatively, they have had a severe soft tissue infection and been incorrectly coded as NF. The validation study of the surgical cohort in 12 centres confirmed over $80 \%$ of cases was correctly coded, suggesting that patients undergoing surgery did have a true diagnosis of NF.

Importantly, a change in isolated pathogenic species over the 10-year period was observed. Although the majority of isolates were staphylococci and streptococci species as in other studies, a falling number of isolated Staphylococcus aureus strains and an increase in Gramnegative species, predominantly E. coli and Klebsiella pneumonia, in the absence of a change in anaerobic species have been demonstrated. These data may reflect the effectiveness of anti-MRSA interventions across UK hospitals, which coincides with the study period [30, 31]. However, this pattern was also seen in patients presenting as an emergency from the community. Polymicrobial NF is the predominant form, and as many as 4 or 5 species may be cultured from cases of NF. The contribution of each isolated organism to the pathogenesis of the disease is often not clear [1, 3, 10]. Although infection is frequently polymicrobial, an increase in monomicrobial NF has also been described in other sites $[1,3,10]$. From HES data, it was not possible to identify a relative change in the 
Fig. 3 Change in pathogens

from patients receiving surgery

over time. Although the

proportion of Gram-positive

organisms overall fell during the

study period, streptococci specii

remained high whilst

staphylococci specii dropped.

Gram-negative isolated specii

became more common, in

particular E. coli

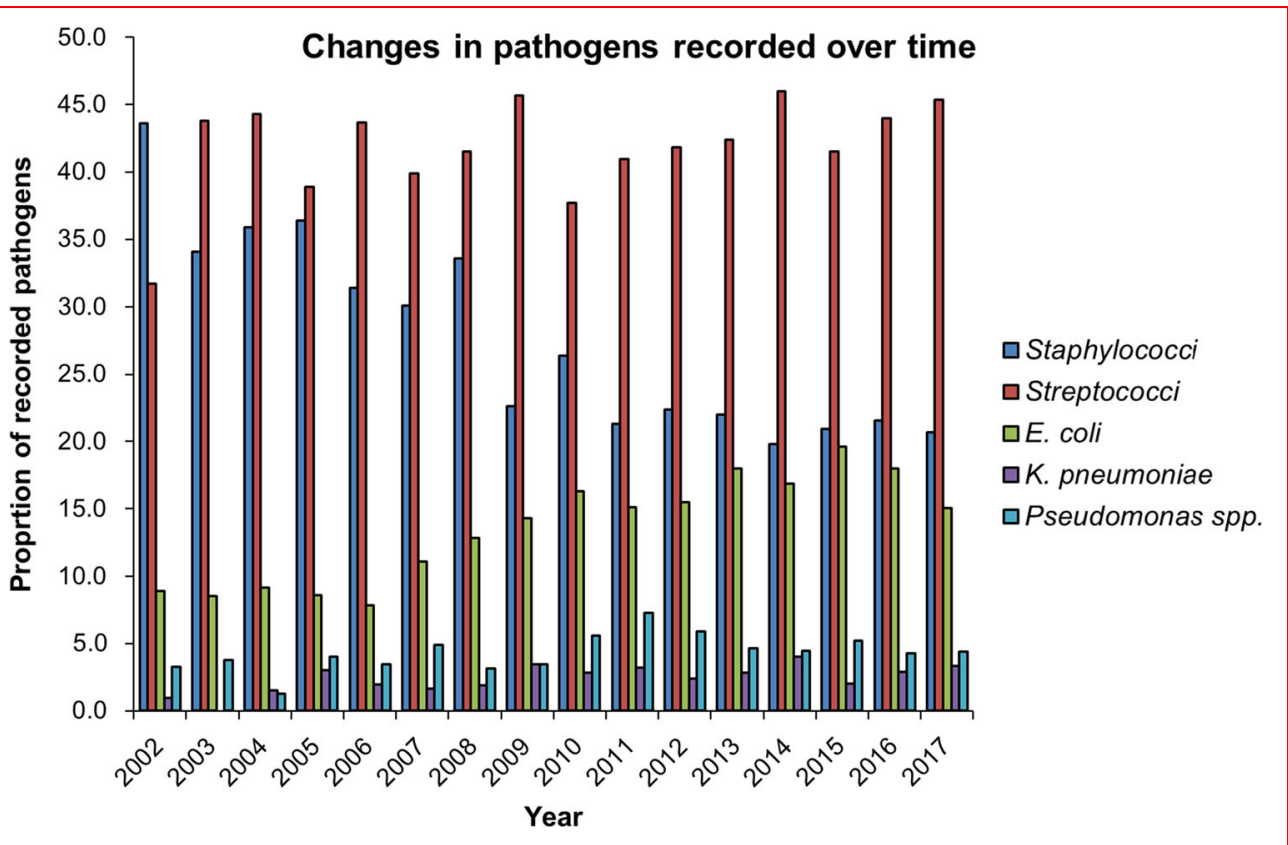

incidence of monomicrobial and polymicrobial NF over time, which may have influenced the relative proportions of species isolated and underestimate responsible organisms. We are only able to comment about the total numbers of pathogens isolated from the cases of NF. The UK Standards for Microbiology Investigations guidelines for processing of samples recommend incubation of samples for investigation of skin, superficial and non-surgical wound swabs in blood agar [32]. Wound swabs from chronic ulcers, traumatic wounds and samples from abscesses and deep-seated wound infections should be cultured in Neomycin fastidious anaerobe agar with metronidazole $5 \mu \mathrm{g}$ disc [33]. We cannot comment on the culture media and conditions used during sample processing over the study period as these were completed by microbiology laboratories across all study sites. Although isolation of anaerobes was low throughout the study period, this may reflect variation in culture techniques between centres. The findings therefore may underestimate anaerobic species.

The increase in Gram-negative infections pathogens isolated from $\mathrm{NF}$ cases has also been recently been reported elsewhere [34-36]. Interestingly, Lee et al. observed more frequent septic shock and higher risk of mortality in patients with Gram-negative monomicrobial NF [37]. It is important to note that the findings from that study were seen in one hospital over a 9-year period with a high incidence of isolated Gram-negative bacilli, predominantly Vibrio species, in $76.1 \%$ of patients. This represents an unusual aetiology in the UK and is likely associated with the different geographical location of the Lee study. The impact of alterations in isolated pathogenic species and the effect of polymicrobial compared to monomicrobial infections on outcome have not been formally evaluated. A change in the balance of pathogens causing NF may have implications for empirical antimicrobial therapy with Gram-negative species presenting the greatest current AMR challenge in hospital medicine.

There are several limitations of this observational approach. The observed increased incidence may be due to greater recognition of NF with improved levels of diagnoses and coding. Whilst the proportion of patients correctly coded in HES cannot be determined, previous publications support the use of routinely collected HES data for research with improving accuracy rates [14, 38]. Further, we validated our findings by auditing a random sample of 12 hospitals, which confirmed the accuracy of $81 \%$ of NF diagnoses for patients receiving surgery. To improve data accuracy and completeness, patients with missing data including gender and age and patients with missing microbiological data were excluded in the analysis of changes in the proportions of causative organisms.

Data on obesity and smoking were not collected, as these were not routinely collected data items in HES over the study period. In the UK, seven of ten British people will be overweight or obese by 2020 with $40 \%$ being obese by 2030 $[39,40]$. As there is a clear association between rising levels of obesity and increasing prevalence of DM, obesity may be a contributing factor to the observed increased incidence of $\mathrm{NF}$, but this could not be determined by this study.

It is clear that a number of aspects of patient care cannot be disclosed by the existing data sources including time of onset and duration of symptoms, severity and prognosis at presentation and diagnosis, management in the community, death in patients who never had surgery due to co-morbid 
disease or NF-related multi-organ failure, reasons for nonsurgical management or choice of antimicrobials, their timing and frequency of administration. These factors impact on outcome, and changes in practice over time including earlier diagnosis, earlier admission to hospital for intervention and advances in intensive care management may explain the observed reduced in-hospital mortality.

\section{Conclusion}

Our results show an increasing incidence of NF in England which is a cause for concern, but a reduction in in-hospital mortality. The time to surgical intervention did not change over the study period. These data support the establishment of a national database to allow an ongoing audit of the observed increased incidence and changes in pathogenic species, which would inform future treatment strategies and improved patient outcome.

Authors contribution DB, IB and FE collected the data. DB, IB, FE, $\mathrm{CW}$ and MW analysed the data. All authors contributed to interpreting the data and to writing and amending the manuscript. All authors have given approval for the manuscript to be published. The authors respectively and fondly remember Prof Woodman who sadly passed away before publication. The corresponding author attests that all listed authors meet authorship criteria and that no others meeting the criteria have been omitted. The lead author, OT, affirms that the manuscript is an honest, accurate and transparent account of the study being reported, that no important aspects of the study have been omitted, and that any discrepancies from the study as planned (and, if relevant, registered) have been explained. There was no funding for this work. All authors have completed the ICMJE uniform disclosure form at http://www.icmje.org/coi_disclosure.pdf and declare: no support from any organisation for the submitted work; no financial relationships with any organisations that might have an interest in the submitted work in the previous three years; and no other relationships or activities that could appear to have influenced the submitted work.

\section{Compliance with ethical standards}

Conflict of interests The author declares that they have no conflict of interest.

Open Access This article is licensed under a Creative Commons Attribution 4.0 International License, which permits use, sharing, adaptation, distribution and reproduction in any medium or format, as long as you give appropriate credit to the original author(s) and the source, provide a link to the Creative Commons licence, and indicate if changes were made. The images or other third party material in this article are included in the article's Creative Commons licence, unless indicated otherwise in a credit line to the material. If material is not included in the article's Creative Commons licence and your intended use is not permitted by statutory regulation or exceeds the permitted use, you will need to obtain permission directly from the copyright holder. To view a copy of this licence, visit http://creativecommons. org/licenses/by/4.0/.

\section{Appendix A: Surgical codes from OPCS-4}

\begin{tabular}{|c|c|c|}
\hline \multirow[t]{7}{*}{ Amputation } & $\mathrm{X} 07$ & Amputation of arm \\
\hline & $\mathrm{X} 08$ & Amputation of hand \\
\hline & X09 & Amputation of leg \\
\hline & $\mathrm{X} 10$ & Amputation of foot \\
\hline & $\mathrm{X} 11$ & Amputation of toe \\
\hline & N261 & Total amputation of penis \\
\hline & N262 & Partial amputation of penis \\
\hline \multirow[t]{10}{*}{ Debridement } & S541 & Debridement of burnt skin of head or neck \\
\hline & S551 & Debridement of burnt skin NEC \\
\hline & S561 & Debridement of skin of head or neck \\
\hline & S571 & Debridement of skin NEC \\
\hline & S573 & Toilet of skin NEC \\
\hline & S581 & $\begin{array}{l}\text { Larvae debridement therapy of skin of head or } \\
\text { neck }\end{array}$ \\
\hline & S582 & Larvae debridement therapy of skin NEC \\
\hline & T774 & Debridement of muscle NEC \\
\hline & T963 & Debridement of soft tissue NEC \\
\hline & Y055 & Debridement of organ NOC \\
\hline \multirow[t]{5}{*}{ Graft } & $\mathrm{S} 35$ & Split autograft of skin \\
\hline & $\mathrm{S} 36$ & Other autograft of skin \\
\hline & $\mathrm{S} 37$ & Other graft of skin \\
\hline & $\mathrm{S} 38$ & Graft of mucosa \\
\hline & S39 & Graft of other tissue to skin \\
\hline \multirow[t]{12}{*}{ Dressing } & S544 & Dressing of burnt skin of head or neck NEC \\
\hline & S545 & $\begin{array}{l}\text { Attention to dressing of burnt skin of head or } \\
\text { neck }\end{array}$ \\
\hline & S547 & $\begin{array}{l}\text { Dressing of burnt skin of head or neck using } \\
\text { vacuum-assisted closure device }\end{array}$ \\
\hline & S554 & Dressing of burnt skin NEC \\
\hline & S555 & Attention to dressing of burnt skin NEC \\
\hline & S557 & $\begin{array}{l}\text { Dressing of burnt skin using vacuum-assisted } \\
\text { closure device NEC }\end{array}$ \\
\hline & S564 & Dressing of skin of head or neck NEC \\
\hline & S565 & $\begin{array}{l}\text { Attention to dressing of skin of head or neck } \\
\text { NEC }\end{array}$ \\
\hline & S567 & $\begin{array}{l}\text { Dressing of skin of head or neck using } \\
\text { vacuum-assisted closure device }\end{array}$ \\
\hline & S574 & Dressing of skin NEC \\
\hline & S575 & Attention to dressing of skin NEC \\
\hline & S577 & $\begin{array}{l}\text { Dressing of skin using vacuum-assisted } \\
\text { closure device }\end{array}$ \\
\hline \multirow[t]{8}{*}{ Drainage } & H58 & Drainage through perineal region \\
\hline & $\mathrm{P} 14$ & Incision of introitus of vagina \\
\hline & $\mathrm{T} 34$ & Open drainage of peritoneum \\
\hline & $\mathrm{N} 244$ & Incision of male periurethral tissue \\
\hline & $\mathrm{P} 131$ & Drainage of female perineum \\
\hline & $\mathrm{X} 125$ & Drainage of amputation stump \\
\hline & N323 & Incision of penis (NEC) \\
\hline & N322 & Drainage of penis \\
\hline
\end{tabular}


Appendix continued

S471 Drainage of lesion of skin of head or neck

S472 Drainage of lesion of skin NEC

S473 Incision of lesion of skin of head or neck

S474 Incision of lesion of skin NEC

S475 Incision of skin of head or neck

S476 Incision of skin NEC

Fasciotomy T55 Release of fascia

\section{References}

1. Hasham S, Matteucci P, Stanley PRW, Hart NB (2005) Necrotising fasciitis. BMJ 330(7495):830-833

2. Goh TG, Ang LG, Wong CH (2014) Early diagnosis of necrotizing fasciitis. Br J Surg 101:e119-e125

3. Stevens DL, Bryant AE (2017) Necrotizing soft-tissue infections. N Engl J Med 377(23):2253-2265

4. Leiblein M, Marzi I, Sander A, Barker J, Ebert F, Frank J (2017) Necrotizing fasciitis: treatment concepts and clinical results. Eur J Trauma Emerg Surg 44(2):279-290

5. Edlich RF, Cross CL, Dahlstrom JJ, Long Iii WB (2010) Modern concepts of the diagnosis and treatment of necrotizing fasciitis. J Emerg Med 39(2):261-265

6. Mulla ZD (2004) Treatment options in the management of necrotising fasciitis caused by Group A Streptococcus. Exp Opin Pharm 5(8):1695-1700

7. Ki V, Rotstein C (2008) Bacterial skin and soft tissue infections in adults: a review of their epidemiology, pathogenesis, diagnosis, treatment and site of care. Can J Infect Dis Med Microbiol 19(2):173-184. PubMed PMID: 19352449. eng.

8. Arif N, Yousfi S, Vinnard C (2016) Deaths from necrotizing fasciitis in the United States, 2003-2013. Epidemiol Infect 144(6):1338-1344. PubMed PMID: 26548496. Epub 11/09. eng.

9. Dworkin M, Westercamp M, Park L, McIntyre A (2009) The epidemiology of necrotizing fasciitis including factors associated with death and amputation. Epidemiol Infect 137(11):1609-1614

10. Giuliano A, Lewis F Jr, Hadley K, Blaisdell FW (1977) Bacteriology of necrotizing fasciitis. Am J Surg 134(1):52-57

11. Bellapianta JL, Tobin KE, Uhl R (2009) Necrotizing fasciitis. J Am Acad Orthop Surg 17:174-182

12. Sarani B, Strong M, Pascual J, Schwab CW (2009) Necrotizing fasciitis: current concepts and review of the literature. J Am Coll Surg 208(2):279-288

13. Nordqvist G, Walldén A, Brorson H, Tham J (2015) Ten years of treating necrotizing fasciitis. Infect Dis 47(5):319-325

14. Das DK, Baker MG, Venugopal K (2011) Increasing incidence of necrotizing fasciitis in New Zealand: a nationwide study over the period 1990 to 2006. J Infect 63(6):429-433

15. Salcido R (2007) Necrotizing fasciitis: reviewing the causes and treatment strategies. Adv Skin Wound Care 20:288-293

16. Khamnuan $\mathrm{P}$, Chongruksut $\mathrm{W}$, Jear-wattanakanok K, Patumanond J, Tantra-worasin A (2015) Necrotizing fasciitis: epidemiology and clinical predictors for amputation. Int J Gen Med 8:195-202

17. Glass GE, Sheil F, Ruston JC, Butler PEM (2015) Necrotising soft tissue infection in a UK metropolitan population. Ann R Coll Surg Engl 97(1):46-51. PubMed PMID: 25519266. Epub 01/

18. Kaul R, McGeer A, Low DE, Green K, Schwartz B, Simor AE (1997) Population-based surveillance for group A streptococcal necrotizing fasciitis: clinical features, prognostic indicators, and microbiologic analysis of seventy-seven cases. Am J Med 103(1):18-24

19. Organisation WH. ICD-10: International statistical classification of diseases and related health problems. World Health Organisation (2004)

20. Centre HaSCI. Office of Population, Censuses and Surveys Classification of Surgical Operations and Procedures, 4th revision 2014 [cited 2013 10.12.13]. Available from: https://systems. hscic.gov.uk/data/clinicalcoding/codingstandards/opcs4

21. Centre HaSI. Quality and Outcomes Framework: online GP practice results database 2012. Available from: https://www.qof. ic.nhs.uk/

22. Stata statistical software: Release 12. College station, TX: Statacorp LP (2011)

23. Statistics OfN (2011) Census: Key Statistics and Quick Statistics for Local Authorities in the United Kingdom 201 [cited 2018]. Available from: http://www.ons.gov.uk/peoplepopulationand community/populationandmigration/populationestimates/bulletins/ keystatisticsandquickstatisticsforlocalauthoritiesintheunited kingdom/2013-10-11-ethnicity-and-country-of-birth

24. Hung CC, Lin SC, Fang SF, Chen CT, Hsieh YC (1996) Clinical manifestations, microbiology and prognosis of 42 patients with necrotizing fasciitis. J Formos Med Assoc 95:917-922

25. Wsrggasrk H (2004) Global prevalence of diabetes: estimates for the year 2000 and projections for 2030. Diabetes Care 27(5): $1047-1053$

26. Martin D, Wright JA (2009) Disease prevalence in the English population: A comparison of primary care registers and prevalence models. Soc Sci Med 68(2):266-274

27. Partnership HQI. National Diabetes Audit Executive Summary 2009-2010. NHS Information Centre (2010)

28. Brady M (2010) The role of primary care in managing chronic kidney disease. Br J Gen Pract 60(575):396-397

29. Phillips LA, Donovan KL, Phillips AO (2009) Renal quality outcomes framework and eGFR: impact on secondary care. QJM 102(6):415-423

30. Sarma JB, Marshall B, Cleeve V, Tate D, Oswald T (2013) Impact of universal screening on MRSA bacteremias in a single acute NHS organisation (2006-12): interrupted time-series analysis. Antimicrob Resistance Infect Control 2(1):2. PubMed PMID: 23316746.

31. Newitt S, Myles PR, Birkin JA, Maskell V, Slack RCB, NguyenVan-Tam JS et al (2015) Impact of infection control interventions

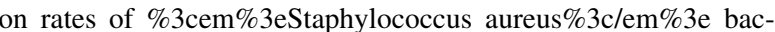
teraemia in National Health Service acute hospitals, East Midlands, UK, using interrupted time-series analysis. J Hosp Infect 90(1):28-37

32. England PH (2014) UK Standards for microbiology investigations: investigation of skin, superficial and non-surgical wound swabs. Bacteriology 5(2):27

33. England PH (2014) UK Standards for microbiology investigations: investigation of abscesses and deep-seated wound infections. Bacteriology 5(2):33

34. Choi S-H, Choi S-H, Kwak YG, Chung J-W, Choo EJ, Kim K-H et al (2012) Clinical characteristics and causative organisms of community-acquired necrotizing fasciitis. Infect Chemother 44(3):180-184

35. Yu SN, Kim TH, Lee EJ, Choo E-J, Jeon MH, Jung YG et al (2013) Necrotizing fasciitis in three university hospitals in Korea: a change in causative microorganisms and risk factors of mortality during the last decade. Infect Chemother 45(4):387-393. PubMed PMID: 24475352. Epub 12/27

36. Yahav D, Duskin-Bitan H, Eliakim-Raz N, Ben-Zvi H, Shaked H, Goldberg E et al (2014) Monomicrobial necrotizing fasciitis in a single center: the emergence of Gram-negative bacteria as a common pathogen. Int J Infect Dis 28:13-16 
37. Lee CYK, Peng KT, Hsu WH, Huang TW, Chou YC (2011)

Prognostic factors and monomicrobial necrotizing fasciitis: gram-positive versus gram-negative pathogens. BMC Infect Dis 11(5)

38. Burns EMRE, Mamidanna R, Bottle A, Aylin P, Ziprin P, Faiz OD (2011) Systematic review of discharge coding accuracy. J Publ Health 34(1):138-148
39. Wang YC, McPherson K, Marsh T, Gortmaker SL, Brown M (2011) Health and economic burden of the projected obesity trends in the USA and the UK. The Lancet 378(9793):815-825

40. F. S. Obesity and the Economics of Preventation: OECD (2010)

Publisher's Note Springer Nature remains neutral with regard to jurisdictional claims in published maps and institutional affiliations. 